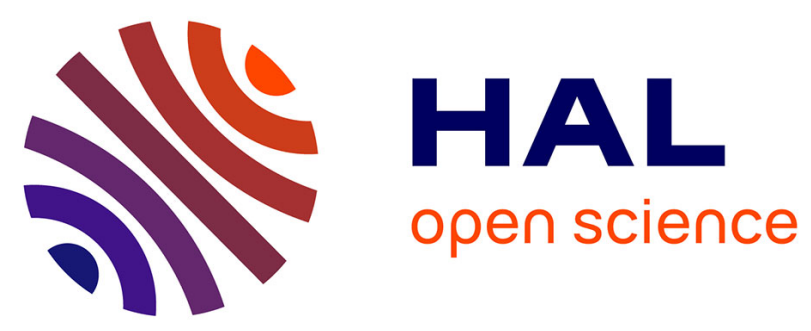

\title{
Ultrasonic wave propagation in reticulated foams saturated by different gases: High frequency limit of the classical models
}

\author{
Philippe Leclaire, Luc Kelders, Walter Lauriks, Christ Glorieux
}

\section{To cite this version:}

Philippe Leclaire, Luc Kelders, Walter Lauriks, Christ Glorieux. Ultrasonic wave propagation in reticulated foams saturated by different gases: High frequency limit of the classical models. Applied Physics Letters, 1996, 10.1063/1.117544 . hal-01326813

\section{HAL Id: hal-01326813 \\ https://hal.science/hal-01326813}

Submitted on 6 Jun 2016

HAL is a multi-disciplinary open access archive for the deposit and dissemination of scientific research documents, whether they are published or not. The documents may come from teaching and research institutions in France or abroad, or from public or private research centers.
L'archive ouverte pluridisciplinaire HAL, est destinée au dépôt et à la diffusion de documents scientifiques de niveau recherche, publiés ou non, émanant des établissements d'enseignement et de recherche français ou étrangers, des laboratoires publics ou privés. 


\title{
Ultrasonic wave propagation in reticulated foams saturated by different gases: High frequency limit of the classical models
}

\author{
Ph. Leclaire, L. Kelders, W. Lauriks, J. F. Allard, and C. Glorieux \\ Laboratorium voor Akoestiek en Thermische Fysica, Departement Natuurkunde, \\ Katholieke Universiteit Leuven, Celestijnenlaan 200D, 3001 Leuven, Belgium
}

\begin{abstract}
Transmission experiments are performed on high porosity reticulated polyurethane foams saturated by different gases at ultrasonic frequencies up to $800 \mathrm{kHz}$. An excess attenuation is observed at high frequencies, when the wavelength is not sufficiently large compared to the lateral dimensions of the fibers. At lower frequencies, these experiments lead by using classical models of equivalent fluids, to a fast and reliable method for determining the characteristic length $\Lambda$.
\end{abstract}

Nagy et al. ${ }^{1}$ have proposed a simple experiment to generate and detect a slow compressional wave in air-filled porous material and natural rocks at ultrasonic frequencies $[70-600 \mathrm{kHz}]$. The measured velocities are in good agreement with the theoretical predictions of Biot ${ }^{2}$ and of Johnson et al. ${ }^{3}$ while an additional attenuation appears at high frequencies. Other experiments were performed by $\mathrm{Nagy}^{4}$ in samples with different permeabilities. It appears that if the wavelength is much greater than the pore size, the attenuation is dominated by the viscous mechanism predicted by the classical theories, ${ }^{2,3}$ while other mechanisms must be invoked as the wavelength decreases. ${ }^{4}$ Similar experiments were made recently in high porosity plastic foams saturated by air or by another gas, in order to measure important parameters that are necessary for the theoretical description of absorbent materials. ${ }^{5}$ The foams investigated are totally reticulated, i.e., the membranes of the bubbles are removed. The parameters determined by this ultrasonic method are the tortuosity, ${ }^{6,7}$ the viscous characteristic length ${ }^{7-9} \Lambda$, defined by Johnson et al. ${ }^{3}$ and the thermal characteristic length ${ }^{9} \Lambda^{\prime}$, defined by Champoux and Allard. ${ }^{10}$ The additional attenuation also occurs for absorbent materials and appears as a limiting factor to the use of the ultrasonic method.

The purpose of this letter is to show the excess attenuation in these materials can mainly be attributed to scattering.

An extensive review of the attenuation mechanisms in sandstones has recently been given by Gist. ${ }^{11}$ Most of the mechanism mentioned by Gist are specific to media saturated by water or by oil studied in geophysics and are not relevant for high porosity foams saturated by air. The phenomena responsible for attenuation are partial saturation, frictional sliding between the solid grains, matrix anelasticity, and nonlinear deformation responses. Other attenuation mechanisms exist and they may apply to porous foams: the thermal exchanges between air and frame, two new mechanisms ${ }^{11}$ occurring when the viscous skin depth is sufficiently small and scattering. The thermal effect has already been accounted for. ${ }^{5,10}$ The two viscous mechanisms are the local flows in microcracks created by the solid grain contacts and on the rough surface of the pore walls. They can decrease the dynamic permeability of the material and substantially increase the wave attenuation at high frequencies when the viscous skin depth becomes smaller than the surface roughness or the dimensions of the microcracks. The viscous skin depth is given by $\delta=\sqrt{2 \nu / \omega}$, where $\nu$ is the kinematic viscosity and $\omega$, the angular frequency. Totally reticulated foams have a quite simple structure. They are constituted of interconnected solid bonds that can be considered, in a first approximation, as cylinders having a circular cross section. The bonds form structures such as dodecahedra, ${ }^{12}$ which are contiguous. Electronic microscopy of reticulated foams ${ }^{12}$ does not show any evidence of microcracks or surface roughness. As a consequence, the excess attenuation observed in reticulated foams cannot be attributed to viscous mechanisms and only scattering must be invoked. This assertion, deduced from qualitative considerations, is confirmed by the experiments presented in this letter, which consist in measuring the attenuation in samples saturated by different gases.

The experimental setup is similar to the one described in Ref. 9 with the difference that the vacuum chamber containing the sample and the transducers can be filled, at atmospheric pressure, with air, helium or Forane 132a $\mathrm{CH}_{2} \mathrm{~F}-$ $\mathrm{CF}_{3}$ (CFC). (This CFC has no bad consequence in the environment after being evaluated out of the chamber). Capacitive transducers ${ }^{13}$ are used to generate and to detect an acoustic pulse propagating in the gas saturating the sample. Mylar films of $6 \mu \mathrm{m}$ thickness are used as vibrating membranes resulting in a frequency range between 50 and 800 $\mathrm{kHz}$. The sound speed $c$ and attenuation $\alpha$ in the material are deduced from the comparison between the amplitude and phase of the reference signal (without the sample between the transducers) and of the signal crossing the sample. The quality factor $Q$, defined as half the ratio of the real to the imaginary part of the wave number $k$, is expressed as a function of $c$ and $\alpha$ by $Q=\omega /(2 \alpha c)$. The asymptotic expression for $k$ at high frequencies ${ }^{6}$ is

$$
k=\frac{\omega}{c_{0}} \sqrt{\alpha_{\infty}}\left[1+(1-j) \frac{\delta}{2}\left(\frac{1}{\Lambda}+\frac{\gamma-1}{\Lambda^{\prime} \sqrt{\mathrm{Pr}}}\right)\right],
$$

where $\alpha_{\infty}$ is the tortuosity, $c_{0}$ the sound speed in the free gas, Pr the Prandtl number, $\Lambda$ and $\Lambda^{\prime}$ the viscous and thermal 


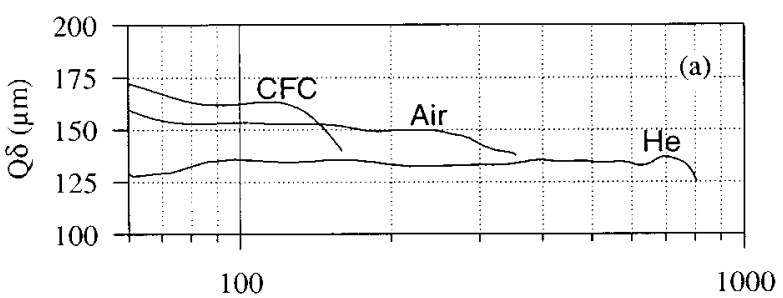

Frequency $(\mathrm{kHz})$

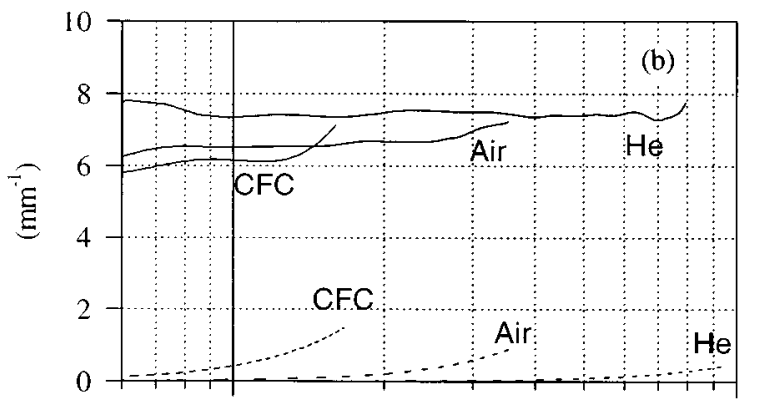

100

1000

Frequency $(\mathrm{kHz})$

FIG. 1. (a) Product of the quality factor $Q$ and the viscous skin depth $\delta$ as a function of frequency for high porosity foams saturated by air, by helium, and by Forane $132 \mathrm{a} \mathrm{CH}_{2} \mathrm{~F}-\mathrm{CF}_{3}$. These curves are experimental results. (b) Comparison between $1 / Q \delta$ (full lines) obtained from the experiments and $\Delta(1 / Q \delta)$ (dashed lines) calculated theoretically (foam 1).

characteristic lengths, and $\gamma$ the specific heat ratio. When the asymptotic expression is valid, the real part of $k$ is close to $\omega \sqrt{\alpha_{\infty}} / c_{0}$ and the product $Q \delta$ is close to

$$
\lim _{\omega \rightarrow \infty} Q \delta=\left(\frac{1}{\Lambda}+\frac{\gamma-1}{\Lambda^{\prime} \sqrt{\operatorname{Pr}}}\right)^{-1} .
$$

The results for two foams are presented. The product $Q \delta$ is plotted in Fig. 1(a) as a function of frequency for a foam made of solid bonds having a diameter of $2 a=60 \mu \mathrm{m}$, a porosity of $\phi=0.97$, and a tortuosity of $\alpha_{\infty}=1.06$ (foam 1). The foam is saturated either by air, or helium, or by CFC. In the example of Fig. 1, the effect of the previously discussed excess attenuation is accounted for through a decrease of the quality factor and a "fall down" of $Q \delta$ starting from a "cutoff' frequency $f_{\infty}$ of about $130 \mathrm{kHz}$ in CFC, $257 \mathrm{kHz}$ in air, and $763 \mathrm{kHz}$ in helium. These results confirm that the excess attenuation cannot be a consequence of a viscous effect. If the decrease of $Q \delta$ is due to a viscous effect, it will occur in helium or in CFC when the viscous skin depth has a similar value as in air. The kinematic viscosity of helium being 7.6 times greater than the one of air (see Table I), the frequency at which the decrease of $Q \delta$ should occur should be 257

TABLE I. Physical properties of air, helium, and Forane 132a $\mathrm{CH}_{2} \mathrm{~F}-\mathrm{CF}_{3}$ at $20^{\circ} \mathrm{C} . P_{0}$ is the atmospheric pressure $\left(P_{0}=1.01 \times 10^{5} \mathrm{~Pa}\right)$.

\begin{tabular}{lccccr}
\hline \hline & $\begin{array}{c}\rho \\
\left(\mathrm{kg} \mathrm{m}^{-3}\right)\end{array}$ & $\begin{array}{c}\nu \\
\left(\mathrm{m}^{2} \mathrm{~s}^{-1}\right)\end{array}$ & $\gamma$ & $\operatorname{Pr}$ & $\begin{array}{c}\sqrt{\gamma P_{0} / \rho} \\
(\mathrm{m} / \mathrm{s})\end{array}$ \\
\hline $\mathrm{Air}$ & 1.2 & $1.54 \times 10^{-5}$ & 1.4 & 0.71 & 344 \\
$\mathrm{He}$ & 0.166 & $11.64 \times 10^{-5}$ & 1.667 & 0.67 & 1007 \\
$\mathrm{CH}_{2} \mathrm{~F}-\mathrm{CF}_{3}$ & 4.24 & $0.247 \times 10^{-5}$ & 1.118 & 0.61 & 163 \\
\hline \hline
\end{tabular}

$\mathrm{kHz} \times 7.6=1.95 \mathrm{MHz}$ and not $763 \mathrm{kHz}$ as observed in Fig. 1(a). In CFC, it should occur at $257 / 6.2=4.1 \mathrm{kHz}$ and not at $130 \mathrm{kHz}$.

What is remarkable is that the ratio of the cutoff frequencies corresponds to the ratio of the limit sound speeds in the sample saturated by the different gases, which is also the ratio of the sound speeds in free gases. From this observation, it can be inferred that the additional attenuation mechanism is due to scattering because scattering amplitude depends on the ratio of wavelength and the size of the scatterer. When replacing a gas by another one in the sample, the speed of sound $c$ in the gas is modified, but the critical wavelength $\lambda_{c}=c / f_{\mathrm{co}} \sqrt{\alpha_{\infty}}$ for which the scattering becomes significant does not change. This implies that the cutoff frequency is multiplied by a factor that is precisely the ratio of the sound speeds in the two gases. The speed of sound at $20{ }^{\circ} \mathrm{C}$ being $1007 \mathrm{~m} / \mathrm{s}$ in helium, $163 \mathrm{~m} / \mathrm{s}$ in CFC, and 344 $\mathrm{m} / \mathrm{s}$ in air (Table I), the factor between the cutoff frequencies in helium and in air must be 2.9 and 2.1 when replacing air by CFC. A good confirmation of this statement is provided by the behavior of $Q \delta$ in Fig. 1 where the corresponding ratios of cutoff frequencies are, respectively, $763 \mathrm{kHz} / 257$ $\mathrm{kHz} \approx 3$ and $257 \mathrm{kHz} / 130 \mathrm{kHz} \approx 2$.

Another confirmation can be obtained with a simple modeling of wave propagation in the foams at high frequencies. The model is carried out by considering the foam as a random distribution of identical hard cylindrical fibers (Neuman cylinders) having a radius equal to the radius $a$ of the bonds, and a number density of fibers $n$ such that $n \pi a^{2}$ $=1-\phi$, where $\phi$ is the porosity of the foam. The porosity of this collection of cylinders is equal to the porosity of the real material. The attenuation due to viscosity and thermal exchange is given by the imaginary part of the wave number $k$ in Eq. (1). When the scattering amplitude is negligible, the wave propagates in an "equivalent fluid" having an intrinsic absorption mean-free-path $l_{a}$ given by

$$
l_{a}=(2 \operatorname{Im}[k])^{-1},
$$

where $k$ is given by Eq. (1). Viscosity and thermal exchange being taken into account, the attenuation due to the elastic scattering by the frame can be calculated by different methods. A review and synthesis of literature on wave propagation in random media can be found in Refs. 14-16. An elastic mean-free-path $l_{\mathrm{sc}}$ can be related to scattering. When $l_{\mathrm{sc}}$ is sufficiently large, the global effect of elastic scattering and intrinsic absorption corresponds to a mean-free-path $l$ given by ${ }^{16}$

$$
l^{-1}=l_{a}^{-1}+l_{\mathrm{sc}}^{-1} .
$$

The scattering mean-free path $l_{\mathrm{sc}}$ can be calculated by using the self-consistent diagrammatic approach. ${ }^{17,18}$ This method was used in acoustics by Kirkpatrick, ${ }^{19}$ Condat, ${ }^{20}$ and Weaver. ${ }^{21}$ The volume of fibers $(1-\phi)$ per unit volume is small in the foams studied (less than 5\%), and around the cutoff frequency, the wavelength is still very large compared to the radius of the bonds. In Ref. 20, the scattering meanfree path is given, in the long wavelength and low concentration limit, and for Neuman cylinders by

$$
l_{\mathrm{sc}}=\left(\frac{3}{4} \pi^{2} a^{4} \operatorname{Re}[k]^{3} n\right)^{-1} .
$$




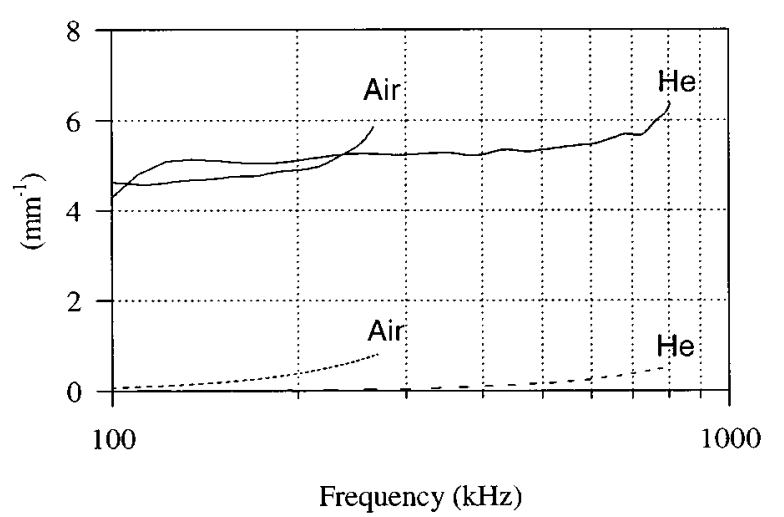

FIG. 2. Comparison between $1 / Q \delta$ (full lines) obtained from the experiments and $\Delta(1 / Q \delta)$ (dashed lines) calculated theoretically (foam 2).

With a definition analogous to Eq. (3), the term $1 / l_{\mathrm{sc}}$ in Eq. (4) corresponds to an increase $\Delta(\operatorname{Im}[k])$ of the imaginary part of $k$ given by

$$
\Delta(\operatorname{Im}[k])=\frac{3}{8} \pi^{2} a^{4} \operatorname{Re}[k]^{3} n .
$$

It can be shown ${ }^{20,22}$ that $\operatorname{Re}[k]$ is a weakly modified by scattering in the long wavelength limit. Then the increase $1 / Q \delta$ is given by

$$
\Delta\left(\frac{1}{Q \delta}\right)=\frac{2 \Delta(\operatorname{Im}[k])}{\delta \operatorname{Re}[k]} .
$$

The measured $1 / Q \delta$ and the calculated $\Delta(1 / Q \delta)$ are compared in Fig. 1(b). Similar results were obtained in other reticulated foams, provided the solid bonds are small enough for the quantity $Q \delta$ to reach a plateau, and large enough to observe the scattering effect. Figure 2 shows the results in air and in He for another foam with solid bonds of a diameter of $80 \mu \mathrm{m}$, a porosity of 0.97 , and a tortuosity of 1.05 (foam 2). The attenuation due to scattering calculated theoretically (dashed curves) corresponds, in magnitude, to the excess attenuation observed experimentally. As predicted, an homothetic ratio of approximately 3 is found between the two curves, considering the frequency scale.

The experimental results presented here show that scat- tering is the main phenomenon responsible for the excess attenuation observed at high frequencies in reticulated foams. It should also be mentioned that the thermal characteristic length $\Lambda^{\prime}$ has no influence in Forane $\mathrm{CH}_{2} \mathrm{~F}-\mathrm{CF}_{3}$, due to the fact that the specific heat ratio of this gas is close to 1 (see Table I). This property can lead to a fast and reliable method to evaluate the viscous characteristic length $\Lambda$ of porous media. Applying this method to foam 1, a value of $165 \mu \mathrm{m}$ is estimated directly from the $Q \delta$ curve obtained in CFC. The interest in this method is that it is simpler and much easier to implement than methods using superfluids He. $^{3,23}$ On the other hand, media encountered in geophysics are not so simple as reticulated porous foams. In these media, viscous losses ${ }^{24}$ can also modify the high frequency asymptotic behavior of the wave.

${ }^{1}$ P. B. Nagy, L. Adler, and B. P. Bonner, Appl. Phys. Lett. 56, 2504 (1990).

${ }^{2}$ M. A. Biot, J. Acoust. Soc. Am. 28, 168 (1956); 28, 178 (1956).

${ }^{3}$ D. L. Johnson, J. Koplik, and R. Dashen, J. Fluid Mech. 176, 379 (1987).

${ }^{4}$ P. B. Nagy, J. Acoust. Soc. Am. 93, 3224 (1993).

${ }^{5}$ J. F. Allard, Sound Propagation in Porous Media: Modeling Sound Absorbing Materials (Elsevier, New York, 1994).

${ }^{6}$ J. F. Allard, B. Castagnède, M. Henry, and W. Lauriks, Rev. Sci. Instrum. 65, 754 (1994).

${ }^{7}$ N. Brown, M. Melon, B. Castagnède, V. Montembault, W. Lauriks, and P. Leclaire, C. R. Acad. Sci. Paris 322, Série IIb, 393 (1996).

${ }^{8}$ P. Leclaire, L. Kelders, W. Lauriks, C. Glorieux, and J. Thoen, J. Acoust. Soc. Am. 99, 1944 (1996).

${ }^{9}$ P. Leclaire, L. Kelders, W. Lauriks, M. Melon, N. Brown, and B. Castagnède, J. Appl. Phys. (to be published).

${ }^{10}$ Y. Champoux and J. F. Allard, J. Appl. Phys. 70, 1975 (1991).

${ }^{11}$ G. A. Gist, J. Acoust. Soc. Am. 96, 1158 (1994).

${ }^{12}$ Low Density Cellular Plastics, Physical Basis of Behaviour, edited by N. C. Hilyard and A. Cunningham (Chapman \& Hall, London, 1994).

${ }^{13}$ D. W. Schindel and D. A. Hutchins, J. Acoust. Soc. Am. 97, 1650 (1995).

${ }^{14}$ D. Sornette, Acustica 67, 199 (1989).

${ }^{15}$ D. Sornette, Acustica 67, 251 (1989)

${ }^{16}$ D. Sornette, Acustica 68, 15 (1989).

${ }^{17}$ W. Götze, Solid State Commun. 27, 1393 (1978).

${ }^{18}$ D. Vollhardt and P. Wölfle, Phys. Rev. B 22, 4666 (1980).

${ }^{19}$ T. R. Kirkpatrick, Phys. Rev. B 31, 5746 (1985).

${ }^{20}$ C. A. Condat, J. Acoust. Soc. Am. 83, 441 (1988).

${ }^{21}$ R. Weaver, Wave Motion 12, 129 (1990).

${ }^{22}$ L. Schwartz and T. J. Plona, J. Appl. Phys. 55, 3971 (1984).

${ }^{23}$ S. R. Baker and I. Rudnik, Proc. IEEE Ultrasonics Symp. 1039 (1985).

${ }^{24}$ P. B. Nagy, J. Acoust. Soc. Am. 99, 914 (1996). 